Correction

\title{
Correction: Fourlakidis, V., et al. Strength Prediction for Pearlitic Lamellar Graphite Iron: Model Validation. Metals 2018, 8, 684
}

\author{
Vasilios Fourlakidis ${ }^{1, *}$, Ilia Belov ${ }^{2}$ and Attila Diószegi ${ }^{2}$ (I) \\ 1 Swerea SWECAST, 55002 Jönköping, Sweden \\ 2 Materials and Manufacturing-Foundry Technology, Jönköping University, Gjuterigatan 5, 55318 Jönköping, \\ Sweden; ilia.belov@ju.se (I.B.); attila.dioszegi@ju.se (A.D.) \\ * Correspondence: vasilios.fourlakidis@swerea.se; Tel.: +46-036-30-12-07
}

Received: 13 December 2018; Accepted: 17 December 2018; Published: 20 December 2018

First of all, the authors would like to apologize for any inconvenience regarding the misleading errors that occurred in the paper.

The following changes should be made:

1. In page 3: Paragraph 3, the correct temperature interval is between 700 and $740{ }^{\circ} \mathrm{C}$.

2. The correct temperature interval in Equation (6) should also be between 700 and $740{ }^{\circ} \mathrm{C}$.

3. Figure 1 should be replaced by the following figure:

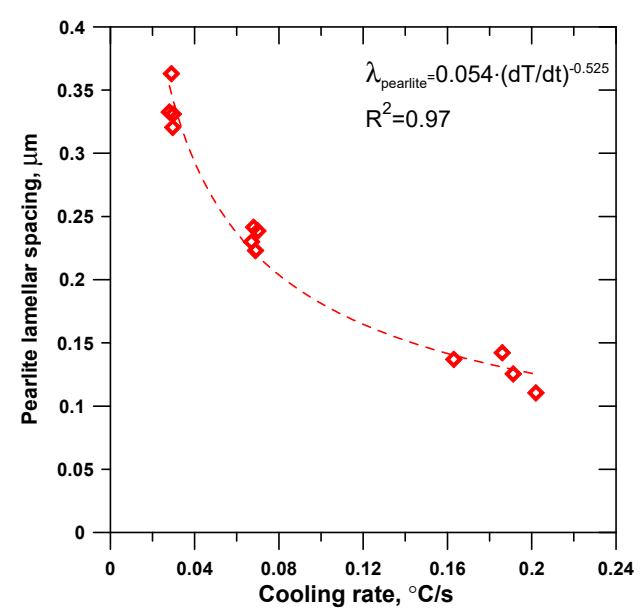

Figure 1. Pearlite lamellar spacing as function of cooling rate between 700 and $740{ }^{\circ} \mathrm{C}$.

4. The correct temperature interval in the title of Figure 1 should be between 700 and $740{ }^{\circ} \mathrm{C}$.

5. The units for specific heat and thermal conductivity in Table 2 should be $[\mathrm{J} / \mathrm{kg} / \mathrm{K}]$ and $[\mathrm{W} / \mathrm{m} / \mathrm{K}]$, respectively.

6. The correct values for the 5 th and 7 th columns in Table 3 are the following: 


\begin{tabular}{c} 
Equation (4) ${ }^{2}$ \\
\hline 200 \\
250 \\
$340-350$ \\
\hline 213 \\
269 \\
$385-395$ \\
\hline 236 \\
300 \\
$435-445$ \\
\hline 253 \\
323 \\
$475-490$ \\
\hline
\end{tabular}

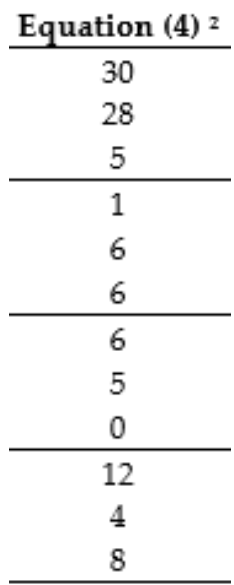

7. Figure 11 should be replaced by the following figure:

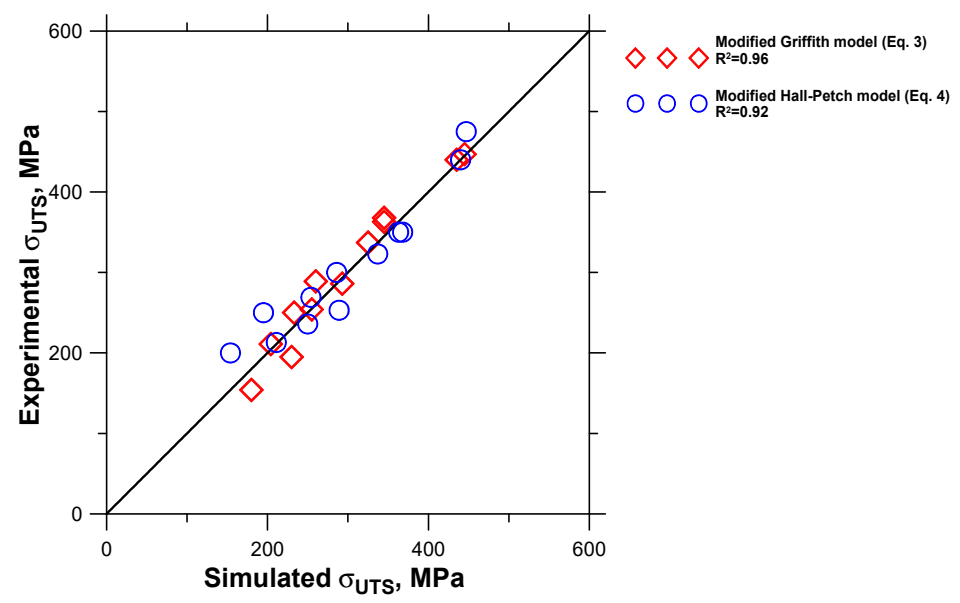

Figure 11. Correlation between measured and simulated UTS values.

8. In Page 11: In paragraph 2 of the Conclusions, in the second sentence, the general agreement within $9 \%$ should be stated.

We apologize for any inconvenience caused to the readers by these changes. The changes do not affect the scientific results. The manuscript will be updated and the original [1] will remain online on the article webpage, with a reference to this Correction.

\section{Reference}

1. Fourlakidis, V.; Belov, L.; Diószegi, A. Strength Prediction for Pearlitic Lamellar Graphite Iron: Model Validation. Metals 2018, 8, 684. [CrossRef] 